\title{
Impacts of a Multi-Purpose Artificial Reef on Hydrodynamics, Waves and Long-Term Beach Morphology
}

\author{
Guilherme Vieira da Silva ${ }^{\dagger \rrbracket}$, Daniel Hamilton $₫$ Thomas Murray $^{\dagger}$, Darrell Strauss ${ }^{\dagger} \llbracket 6$ aeed Shaeri ${ }^{\natural}$, Gaelle \\ Faivre $^{\dagger}$, Ana Paula da Silva ${ }^{\dagger}$, and Rodger Tomlinson ${ }^{\dagger}$
}

\author{
$\dagger$ Griffith Centre for Coastal \\ Management Gold Coast, QLD \\ Australia
}

\author{
$\square$ City Assets, Transport and \\ Infrastructure City of Gold \\ Coast, Australia
}

$\$$ Charles Sturt University Bathurst, NSW

Australia

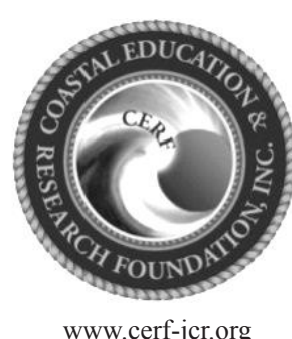

www.cerf-jcr.org



www.JCRonline.org

\begin{abstract}
Vieira da Silva, G.; Hamilton, D.; Murray, T.; Strauss, D.; Shaeri, S.; Faivre, G.; Silva, A.P., and Tomlinson, R., 2020. Impacts of a multi-purpose artificial reef on hydrodynamics, waves and long-term beach morphology. In: Malvárez, G. and Navas, F. (eds.), Global Coastal Issues of 2020. Journal of Coastal Research, Special Issue No. 95, pp. 706-710. Coconut Creek (Florida), ISSN 0749-0208.

Multipurpose Artificial Reefs (MPARs) are structures placed in the nearshore to protect the coast, enhance surfing conditions and ecology. Narrowneck reef is the first MPAR aimed to protect the coast with secondary goal of enhance surfing. Since then, few other structures such as Narrowneck have been deployed and limited data is available in terms of their performance. This paper looks into the impacts the reef has on hydrodynamics, waves and morphologic changes. The results indicate that the reef acts as a hold point deflecting the longshore currents and changing the sediment pathway which resulted in morphological changes observed over longer term. Whilst expected during the design phase of the reef a long-term salient is not observed in the historical record. The primary reef impacts are observed underwater where an increase of sand volume updrift of the reef is clear. This highlights the importance of analysing the whole profile as opposed to the shoreline changes to assess long-term impact of such nearshore structures.
\end{abstract}

ADDITIONAL INDEX WORDS: MPAR, nearshore morphology, coastal structure, beach protection.

\section{INTRODUCTION}

Multipurpose Artificial Reefs (MPARs) are submerged structures that aim to protect the coast, improve surfing and enhance ecology. To date only few structures have been built with both coastal protection and surfing goals and the monitoring data is poor, sparse and/or underreported. While these structures are somehow similar to low-crested breakwaters, the main difference is that their intention is to dissipate just enough energy so that the coastline is protected, and waves can still be surfed.

The MPARs built to date present different shapes, volumes, distances from shoreline and have been deployed in different varying coastal environments (Ng. et al., 2013). This may explain why there are no standards or guidelines in the literature to build such structures. Furthermore, Ranasinghe and Turner (2006) highlighted that most submerged structures have induced erosion in their lee which emphasizes the challenge of designing and constructing these structures.

In order to obtain a more comprehensive understanding of morphological changes caused by MPARs and their drivers to inform future works, this paper combines both long- and shortterm analysis of Narrowneck reef (Queensland, Australia - Fig.1). The aim of this paper is to analyse short-term impact on currents

DOI: 10.2112/SI95-137.1 received 31 March 2019; accepted in revision 13 February 2020.

*Corresponding author: g.vieiradasilva@griffith.edu.au

${ }^{\circ}$ Coastal Education and Research Foundation, Inc. 2020 and wave transformation based on recent instrumentation data collected around the reef and relate to the changes observed in the long-term full beach profile data.

\section{Background}

The Gold Coast is located in Queensland's southeast coast (Figure 1) where the offshore waves (- 70m depth) are lower than $1.5 \mathrm{~m}$ during $50 \%$ of the time (Vieira da Silva et al., 2018), however, episodic extreme events and large erosion have been documented since early 1900's. In 1923 a timber seawall was constructed at Narrowneck to contain erosion. In 1967, four tropical cyclones (TCs) and three east coast lows (ECLs) caused major erosion along the Gold Coast beaches (Splinter et al., 2014). Following the erosion, the beach scarp was fixed using the available material at the time (including rocks, sand bags, concrete aggregates and car bodies) to protect beachfront properties and prevent further erosion (Bowra et al., 2011). This last line of defence on the Gold Coast is known as the A-line. Since then, a series of survey lines (ETA lines) have been stablished and regularly surveyed. In 1974, a large-scale nourishment $\left(1.5 \mathrm{Mm}^{3}\right)$ replenished the northern beaches (Jackson et al., 2012). The nourishment dispersed and the boulder wall at Narrowneck was again exposed in 1990's. In response, the Northern Gold Coast Beach Protection Strategy (NGCBPS) was developed and included (Jackson et al. 2012): (1) Nourishment $\left(1.3 \mathrm{Mm}^{3}\right)$ to widen the beaches; (2) Coastal control point - artificial submerged reef designed to hold the nourishment 


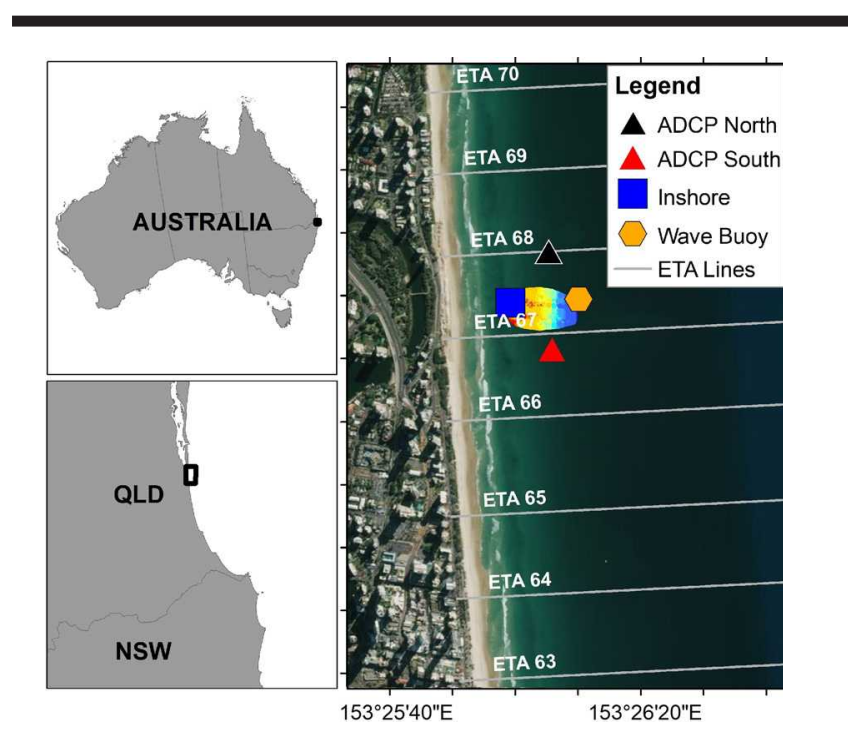

Figure 1. Study area and instrumentation location.

and improve surfing; (3) Permanent pipeline/boosters to facilitate nourishment; (4) Management policies.

The beaches were nourished in 1999 followed by the construction of Narrowneck reef - the world's first multi-purpose artificial reef aimed to help protecting the coastline and improve surfing conditions. The reef was constructed using large geotextile containers filled with sand and extends $500 \mathrm{~m}$ cross-shore and $350 \mathrm{~m}$ alongshore with overall volume of approximately 70,000 $\mathrm{m}^{3}$ (Figure 1).

Following this, the reef has been maintained or 'topped up' with additional sand bags in 2002, 2004, 2006 and 2017. Since its construction Narrowneck reef has been monitored (Jackson et al., 2007; 2012; Ranasinghe and Turner, 2006) generally on a project needs basis. Most of the monitoring is focused on shoreline changes (e.g. Ranasinghe and Turner, 2006), however, Strauss et al. (2017) and Vieira da Silva et al. (2019) indicated that most of Narrowneck impact happens underwater. This paper seeks to build on this hypothesis by assessing the long-term morphological changes supported by a short-term nearshore wave and current experiment.

\section{METHODS}

The methods used in this research were divided into two complementary parts: Instrumentation (short-term) and beach morphology (long-term). While the first method provides a detailed understanding of the reef influence on currents and waves around the reef, the second one provides the long-term morphological evolution as a result of the changes in currents and waves.

\section{Instrumentation}

To understand the impact the reef has on the surrounding hydrodynamics a series of instruments were deployed to measure both waves and currents (Figure 1) as follows:

Offshore: a wave buoy (Spoondrift) and an RBR pressure gauge were deployed at approximately $10 \mathrm{~m}$ water depth between March $14^{\text {th }}$ and April $16^{\text {th }}, 2019$;

- Spotter: Wave parameters (Hs, Tp, Dirp) were measured every 30 minutes from $14 / 03 / 2019$ to $16 / 04 / 2019$. The data processing consisted of removing spikes in the timeseries following Goring and Nikora (2002).

- RBR: was deployed at the bottom (near the wave buoy anchor) to measure waves and compare with the inshore RBR and analyse the wave transformation over the reef. This RBR was set to measure pressure continuously at 4Hz. The processing followed Tucker and Pitt (2001). Firstly, the pressures were corrected based on the atmospheric pressure measured at the Gold Coast Seaway, then the depth attenuation of pressure was corrected, and the tide signal removed. The time series was processed in the frequency domain to derive the wave parameters $(\mathrm{Hm} 0$, Tp).

Inshore: A sled with an ADCP (Sontek Argonaut 3MHz) and an RBR was deployed immediately inshore of the northern part of the reef ( $5.5 \mathrm{~m}$ water depth). The instruments measured data from April $2^{\text {nd }}$ to $7^{\text {th }}(124 \mathrm{~h} 30 \mathrm{~min})$ before becoming buried by an offshore migration of the bar.

- ADCP: has a blanking distance of $0.2 \mathrm{~m}$ and was deployed $0.4 \mathrm{~m}$ above the seabed with bin size of $0.6 \mathrm{~m}$, and a burst interval of 30 minutes and 5 minutes for waves and currents, respectively. Magnetic declination was corrected $\left(11.27^{\circ} \mathrm{E}\right)$ using the International Geomagnetic Reference Field (IGRF) model provided by NOAA (Thébault et al., 2015). Data with signal-to-noise ratio (SNR) below $3 \mathrm{~dB}$ were removed. Then, spikes in the data were removed following Goring and Nikora (2002).

- $\quad$ RBR: measured pressure continuously at $4 \mathrm{~Hz}$ to be compared to the offshore deployment. The data was processed following the same procedures as the offshore RBR.

North and South: Two ADCPs (LinkQuest Flowquest 1MHz), one north (at $5.5 \mathrm{~m}$ water depth) and one south (at $7.5 \mathrm{~m}$ water depth) of the reef between March $14^{\text {th }}$ and April 16 $6^{\text {th }}, 2019$. Both instruments were mounted at the bottom on a tripod looking up to measure currents in $\mathrm{U}$ and $\mathrm{V}$ directions through the water column. The instruments were setup to collect data every 20 minutes with the same configuration: Distance from bottom: $0.59 \mathrm{~m}$; Blank: $0.4 \mathrm{~m}$; Bin size: $0.5 \mathrm{~m}$; Pings per ensemble: 256. Data processing followed the procedures used to process the ADCP inshore.

\section{Beach Morphology}

Beach profile surveys have been carried out on the Gold Coast since the 1960's. The main survey lines (so called ETA lines) cover the entire coast from the top of the dune to the depth of closure at $400 \mathrm{~m}$ spacing. The coverage, however is variable in both space and time. Nonetheless, the dataset is useful in understanding long-term changes in both upper beach and nearshore profile and volume. For the present study, data between ETA 63 and ETA 70 (Figure 1) was analysed in order to discern long-term trends in morphodynamic response related to the Narrowneck reef. To do so, profile lines were grouped into three periods: (1) Eroded period (from the start of the surveys to 1984), following the 1960's and 1970's major events; (2) Pre-reef construction (between 1984 and 1998) and; (3) Post-reef construction (2002 to 2016): starting one year following the completion of the reef and finalising before the major nearshore nourishment conducted by the City of Gold Coast in 2017-18. For each period the average profile was calculated, and the differences were used to understand the long-term impact of the reef in the nearshore region. 


\section{RESULTS}

As with the methods, the results are split into two parts: Beach Morphology and Instrumentation.

\section{Instrumentation}

Measured waves offshore and inshore of Narrowneck reef (Figure 2) indicate that, for the period of measurement, the reef acts to dissipate wave energy, particularly for waves higher than $1.5 \mathrm{~m}$. During the study period the waves attenuated around $15 \%$. It is hypothesised a higher attenuation for higher waves and during low tides. For smaller waves they may shoal over the reef (increasing wave height). Depending on the sand bar position this is hypothesised to improve surfing conditions inshore of the reef as indicated by Jackson et al. (2007). Furthermore, apart from attenuating wave energy and reduction of its height, as waves propagate over the reef, the energy is transferred from the peak frequency to both higher and lower frequencies (Figure 2). It is highlighted that this analysis is highly dependent on: (1) sensor placement; (2) wave height and direction; (3) directional spreading. It is likely that slight changes of sensor position (especially the inshore instrument) would change the results. Corbett (2017) indicated that waves breaking close to the instrument and tridimensional / scatter effects over complex bathymetry may affect the results which indicates a high dependence of the attenuation values with the instrument location.

Currents measured to the north and south of the reef (33 days) are presented in (Figure 3a). While currents measured to the south

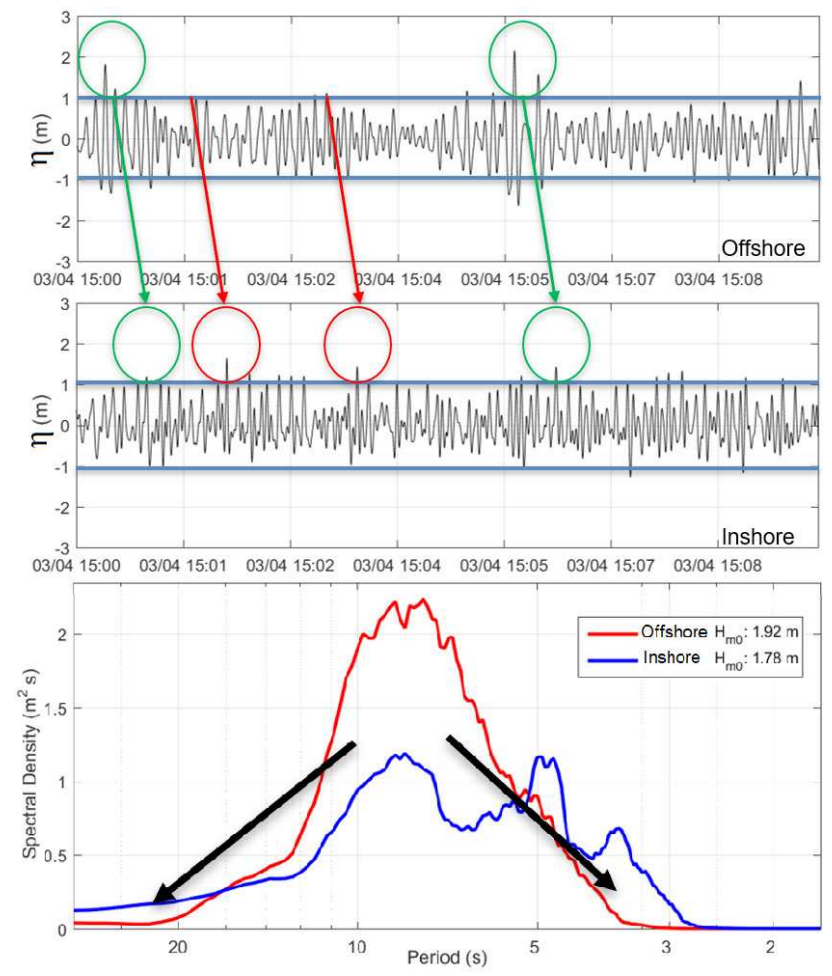

Figure 2. Measured water surface elevation $(\eta, m)$ timeseries offshore (top) and inshore (centre) of Narrowneck reef and spectral density (bottom) offshore (red) and inshore (blue). Green circles indicate waves attenuating over the reef whereas red circles are waves shoaling over the reef. Blue straight lines are used as reference.

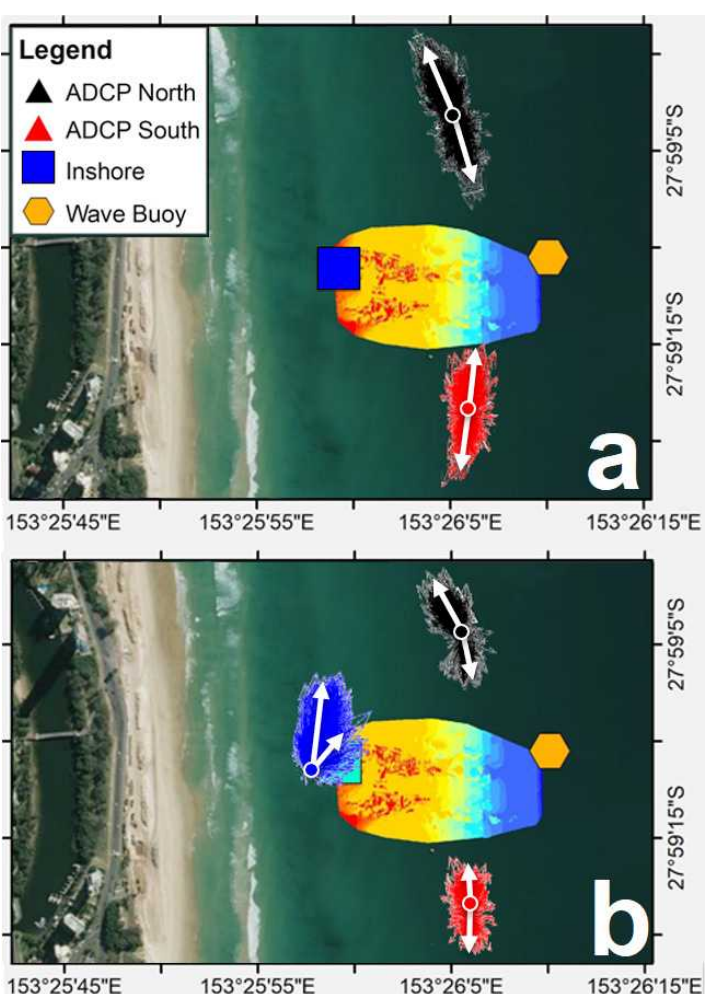

Figure 3. (a) Currents measured during the 33 days by the ADCPS at south (red) and north (black) of the reef; (b) currents measured during 7 days when the ADCP inshore (blue) was deployed. Stacked current vectors (arrows indicate direction to which the currents are heading, and vector size indicate their speed). White arrows indicate the main current directions.

of the reef are generally oriented SSW-NNE, currents measured to the north are oriented SSE-NNW indicating a deflection of the longshore current as it interacts with the offshore part of the reef. The deflected current is likely to be the driver of sediment transport that can lead to the long-term sand accumulation updrift of the reef. Currents measured by the ADCP on the north side of the reef presented higher speeds (Figure 3a,b). This is likely to be related to the depth where it was deployed (-7.5 m AHD) as opposed to $-5.5 \mathrm{~m}$ AHD of the ADCP deployed to the south.

Figure $3 \mathrm{~b}$ shows the stacked vectors of depth averaged currents at the location of the three ADCPs. Instruments deployed updrift and downdrift of the reef measured currents in both directions. This indicates that the driving force is the wind modulated by tides whereas the currents measured inshore of the reef are mainly to the north indicating a wave-driven (longshore/circulation cells formed by the presence of the reef) current. Wind-driven currents tend be dominant offshore and closer to the shore the wave-driven longshore current tends to dominate. When the wind-driven currents flow in the opposite direction of the wave-driven currents, they will reduce their speeds; the closer they get to the "pivot" point, which is located around the reef position for the period of the deployment.

\section{Morphological Changes}

Figure 4 presents the morphological changes around Narrowneck reef comparing the average for the eroded period (1967-1984) to the pre-construction period (1984-1998). Although this analysis precedes the reef construction, Figure 4 displays the reef for 
reference. The longshore changes in sediment volumes $\left(\mathrm{m}^{3} / \mathrm{m}\right)$ were calculated at four areas to be compared to the pre and post construction (Figure 5): (1) inshore updrift; (2) inshore downdrift; (3) offshore updrift and; (4) offshore downdrift. During this period the average profiles indicate an onshore sediment transport with very similar increase inshore of the reef for updrift $(220$ $\left.\mathrm{m}^{3} / \mathrm{m}\right)$ and downdrift $\left(218 \mathrm{~m}^{3} / \mathrm{m}\right)$. Offshore of the reef reduction in lower profile volume is experienced both updrift $\left(-270 \mathrm{~m}^{3} / \mathrm{m}\right)$ and downdrift $\left(-270 \mathrm{~m}^{3} / \mathrm{m}\right)$. The data indicates that, prior to the reef construction the whole section of the beach behaved similarly, as would be expected of an open coast beach.

Volume changes comparing the average profiles pre and post Narrowneck construction (Figure 5) indicate that the reef does have a long-term impact on the surrounding morphology/ morphodynamics, particularly in the nearshore zone. During the post-construction period an increase of $270 \mathrm{~m}^{3} / \mathrm{m}$ was observed updrift of the reef while downdrift the increase was of $180 \mathrm{~m}^{3} / \mathrm{m}$, this indicates that the reef has been acting as a control structure partially trapping the sand that is transported from south to north on the Gold Coast. Offshore of the reef the impact is also observed with an increase of $69 \mathrm{~m}^{3} / \mathrm{m}$ updrift of the reef and while downdrift a decrease of $87 \mathrm{~m}^{3} / \mathrm{m}$ was observed. The results also indicate

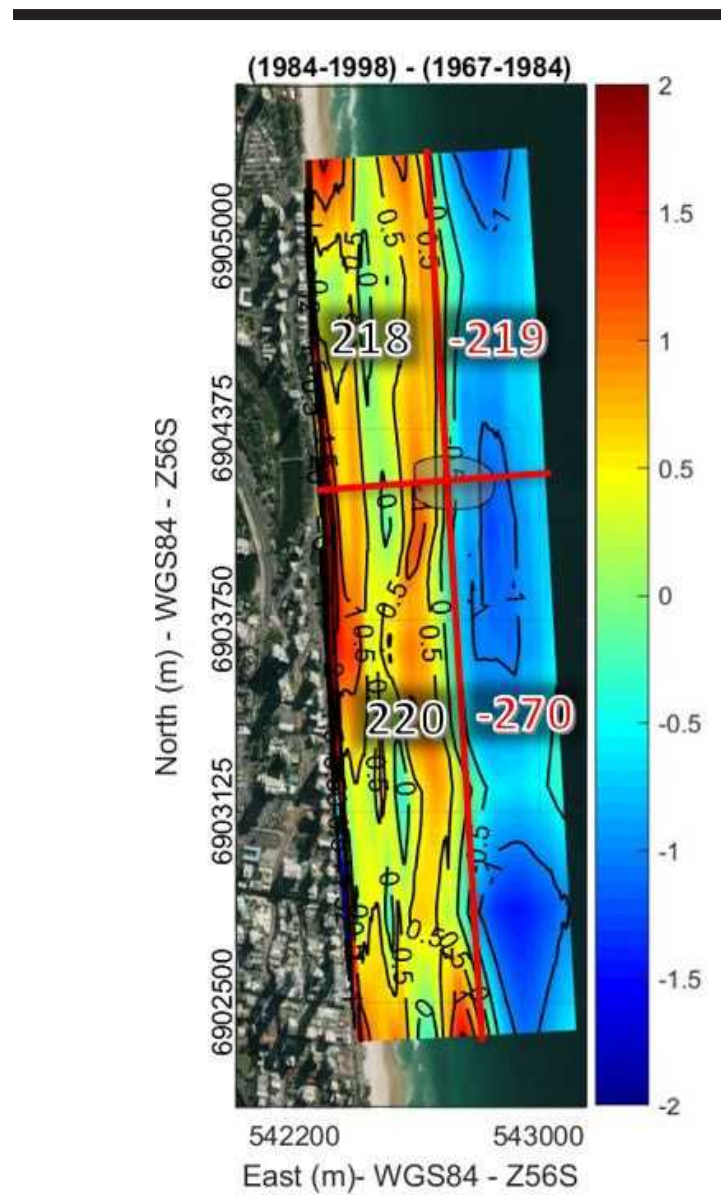

Figure 4. Morphological changes around the Narrowneck reef study site between the eroded period (average profile between 1967-1984) and the pre-construction period (average profile between 1984-1998). Shaded grey area indicates the eventual reef location, red lines the areas where the volumes were calculated $\left(\mathrm{m}^{3} / \mathrm{m}\right)$.



Figure 5. Morphological changes around Narrowneck reef pre (average profile between 1984-1998) and post (average profile between 2002-2016) construction. Shaded grey area indicate the reef location, red lines the areas where the volumes were calculated $\left(\mathrm{m}^{3} / \mathrm{m}\right)$.

potential sediment pathways: (1) inshore of the reef, continuing alongshore aligned with the inshore part of the reef and, (2) sand accumulated updrift of the reef seems to be able to bypass the reef around its offshore part.

\section{DISCUSSION}

In the short-term the reef affects the currents that are deflected around it shifting direction (observed in all instruments). MPARs, as opposed to submerged breakwaters, are built to dissipate just enough wave energy so that the wave can still be surfed. Based on a short deployment (7 days), Narrowneck seems to dissipate wave energy for waves higher than $1.5 \mathrm{~m}$, particularly during low tides. This analysis is based on two instruments and, as indicated by Corbett (2017), the location of the instrument placed between the reef and the coast may significantly change the results. The area in the lee side of the reef presents great spatial variability in wave height due to wave direction and directional spreading / presence of the multiple swell/sea conditions.

The long-term topo-bathymetric survey analysis indicated that following the 1960's and 1970's storms there was an onshore migration of the sediments with very similar rates along the analysed area. By comparing the volume of sediment (up and downdrift) pre- and post-Narrowneck construction, a long-term impact, which the reef has on its surroundings, becomes clear despite the nourishment campaigns that have happened in the area. While very little longshore variability on the upper beach volumes are observed, below the mean sea level is where most 
of the impact is experienced, corroborating Strauss et al. (2017) findings. Updrift of the reef, there was an increase of volume both inshore and offshore of the reef. This is linked with the observed deflection of the currents around the reef and is likely to be a pathway of sediments during more energetic conditions. Downdrift of the reef a lower increase of volume is observed (compared to updrift) inshore of the reef and the greater impact is aligned with the inner portion of the reef. Likely driven by the longshore currents (net direction towards the north on the Gold Coast beaches).

Despite the anticipated shoreline salient (Turner et al., 1999), the long-term averages do not indicate that one is formed and sustained in the long-term. In fact, very little effect of the reef on the upper beach can be observed in the long-term record. Nonetheless, in the sub-tidal region the updrift profiles are shallower, particularly when compared to the downdrift profiles. Shallower profiles will further dissipate wave energy and increase wave attenuation. As a result, the upper beach erosion should be reduced.

\section{CONCLUSIONS}

Multipurpose Artificial Reefs are structures placed in the ocean with at least two of the following aims: (1) protect the coast; (2) enhance surfing and; (3) enhance ecology. Narrowneck reef was the first MPAR deployed in the world aimed to protect the coast and enhance surfing. Twenty years past its construction there is still much knowledge to be gained on these types of structures.

This paper analysed the long-term morphological changes around the reef as well as the reef's impacts on hydrodynamics and wave propagation. Currents measured around the reef are deflected by its presence and indicate the pathways of sediment transport. The deflection of currents around the reef corroborates the observed long-term morphological changes captured in the survey and indicates that the reef acts as a hold point for sand that migrates north along the coast, with higher accumulation of sand observed updrift of the reef.

Results presented here indicate an updrift accumulation of sand which should benefit its main aim of coastal protection by increasing wave energy dissipation as they approach the shoreline and, as a result, reducing upper beach erosion. The wave data indicate that waves higher than approximately $1.5 \mathrm{~m}$ dissipate wave energy potentially reducing upper beach erosion on the lee of the reef and creating surfable waves. Analysis of surfing wave quality is, however, out of scope of this paper.

Despite being expected during design/construction phase of the reef, a salient was not observed in the long-term survey trends. Most of the reef's impact on morphology occurs underwater. Subaerial profiles and shoreline position are important measures of beach amenities. However, the results presented here demonstrate that to fully understand the impacts of MPARs, it is important to analyse the entire profile, where most of the morphological changes are observed.

\section{ACKNOWLEDGMENTS}

This research project was sponsored by the City of Gold Coast (the City) through a funding and collaboration agreement between the City and Griffith University. The City has provided data, including bathymetric survey, and project overview to assist in the understanding of this research topic and its benefit to the City.

\section{LITERATURE CITED}

Bowra, K.; Hunt, S.; McGrath, J., and Pistol, D., 2011. Last Line of Defence - Seawalls. Gold Coast City Council. Queensland Coastal Conference, 2011, Cairns.

Corbett, B., 2017. Design Report: Renewal works at Narrowneck artificial reef. Prepared for the City of Gold Coast by International Coastal Management. $69 \mathrm{pp}$.

Goring, D.G. and Nikora, V.I., 2002. Despiking Acoustic Doppler Velocimeter Data. Journal of Hydraulic Engineering. 128, (1), 117 - 126 .

Jackson, A.; Tomlinson, R.; Corbett, B., and Strauss, D., 2012. Long term performance of a submerged coastal control structure: a case study of the Narrowneck multi-functional artificial reef. Proceedings of International Coastal Conference on Coastal Engineering 2012. Santander, Spain.

Jackson, L.A.; Corbett, B.B., McGrath, J.E.; Tomlinson, R.B., and Stuart, G., 2007. Narrowneck reef: Review of seven years of monitoring. Shore \& Beach. 75 (4), 1-13.

Ng., K.; Phillips, M.R.; Calado, H.; Borges, P., and VelosoGomes, F. 2013. Seeking harmony in coastal development for small islands: Exploring multifunctional artificial reefs for Sao Miguel Island, the Azores. Applied Geography (44), 99-111.

Ranasinghe, R. and Turner, I.L., 2006 Shoreline response to submerged structures: a review. Coastal Engineering, (53), 65-79.

Splinter, K.D.; Carley, J.T.; Golshani, A., and Tomlinson, R., 2014. A relationship to describe the cumulative impact of storm clusters on beach erosion. Coastal Engineering (83), 49-55.

Strauss, D.; Murray, T.; Harry, M., and Todd, D., 2017. Coastal data collection and profile surveys on the Gold Coast: 50 years on. Proceedings of Coasts \& Ports 2017 - Cairns, 2123 June 2017.

Thébault, E.; Finlay, C.C.; Beggan, C.D.; Alken, P., and Aubert, J., et al., 2015. International Geomagnetic Reference Field: the $12^{\text {th }}$ generation. Earth, Planets and Space, 67, 19pp.

Tucker, M.J. and Pitt E.G., 2001 Waves in ocean engineering. Elsevier ocean engineering book series vol. 5, Elsevier, Amsterdam, $521 \mathrm{p}$.

Turner, I.L.; Leyden, V.M.; Cox, R.J.; Jackson, A., and McGrath, J.E., 1999. Three-Dimensional Scale Physical Model Investigations of the Gold Coast Artificial Reef. In: Proceedings of the 14th Australasian Coastal and Ocean Engineering Conference \& 7th Australasian Port and Harbour Conference, Coasts \& Port; 1999.

Vieira da Silva, G.; Murray, T., and Strauss, D., 2018. Longshore wave variability along non-straight coastlines. Estuarine, Coastal and Shelf Science (212), 318-328. doi.org/10.1016/j. ecss.2018.07.022.

Vieira da Silva, G.; Strauss, D.; Shaeri, S.; Murray, T.; Tomlinson, R., and Hamilton, D., 2019. Longshore sediment interruption and bypassing of a multipurpose artificial reef - preliminary results. Proceedings of the $9^{\text {th }}$ international conference on Coastal Sediments, 2019, Tampa/St. Petesburg, USA, May, 2019. https://doi.org/10.1142/9789811204487_0236. 